\title{
Borderline Ovarian Seromucinous Tumor/Atypical Proliferative Ovarian Seromucinous Tumor
}

National Cancer Institute

\section{Source}

National Cancer Institute. Borderline Ovarian Seromucinous Tumor/Atypical Proliferative

Ovarian Seromucinous Tumor. NCI Thesaurus. Code C7281.

A low grade, non-invasive mixed epithelial proliferative neoplasm that arises from the ovary. It is composed predominantly of serous and endocervical-type mucinous cells. 